\title{
Design of a Mach-3 Nozzle for TBCC Testing in the NASA LaRC 8-Ft High Temperature Tunnel
}

\author{
Richard L. Gaffney, Jr. * \\ Andrew. T. Norris * \\ NASA Langley Research Center, Hampton, Virginia, 23681-2199, U.S.A
}

\begin{abstract}
A new nozzle is being constructed for the NASA Langley Research Center 8-Foot High Temperature Tunnel. The axisymmetric nozzle was designed with a Mach-3 exit flow for testing Turbine-Based Combined-Cycle engines at a Mach number in the vicinity of the transition from turbojet to ramjet operation. The nozzle contour was designed using the NASA Langley IMOCND computer program which solves the potential equation using the classical method of characteristics. To include viscous effects, the design procedure iterated the MOC contour generation with CFD Navier-Stokes calculations, adjusting MOC input parameters until target nozzle-exit conditions were achieved in the Navier-Stokes calculations. The design process was complicated by a requirement to use the final 29.5 inches of an existing 54.5-inch exit-diameter Mach-5 nozzle contour. This was accomplished by generating a Mach-3 contour that matched the radius of the Mach-5 contour at the match point and using a 3rd order polynomial to create a smooth transition between the two contours. During the final evaluation of the design it was realized that the throat diameter is more than half that of the upstream mixing chamber. This led to the concern that large vortical structures generated in the mixer would persist downstream, affecting nozzle-exit flow. This concern was addressed by analyzing the results of three-dimensional, viscous, numerical simulations of the entire flowfield, from the exit of the facility combustor to the nozzle exit. An analysis of the solution indicated that large scale structures do not pass through the throat and that both the total temperature and species $\left(\mathrm{CO}_{2}\right)$ are well mixed in the mixer, providing uniform flow to the nozzle and subsequently the test cabin.
\end{abstract}

\section{Introduction}

NASA's successful demonstration of scramjet powered flight at Mach numbers of 7 and 10 in 2004 has reinvigorated the nation's interest in hypersonic flight. The U.S. Navy has been investigating hypersonic missile technology with their HyFly program which had the goal of flight testing the Dual Combustion Ramjet design at Mach numbers up to about 6. Similarly, the U.S. Air Force in conjunction with DARPA, is developing scramjet propulsion technology in the Scramjet Engine Demonstration program which will culminate with the flight of their X-51A demonstration vehicle in 2009. DARPA also has the Falcon program which involves the development of a Hypersonic Cruise Vehicle (HCV). Ideas for the HCV include both scramjet propulsion for high Mach number flight and turbojet engines for subsonic and supersonic flight up to Mach 4. This multiple engine concept, with turbojet and scramjet engines sharing parts of the flowpath, is called a TBCC (Turbine-Based Combined-Cycle) propulsion system. An example of a TBCC configuration is given in Figure 1.

One of the challenges in the development of TBCC propulsion systems is the transition of the propulsion system from one engine to the other. This will require a large ground based test facility that can accommodate a dual propulsion flowpath vehicle. NASA's 8-Foot High Temperature Tunnel (8-Ft HTT) at Langley Research Center (LaRC) is a large scale facility that has been used to test high speed engines at simulated

\footnotetext{
*Aerospace Engineer, Hypersonic Air breathing Propulsion Branch, Senior Member AIAA.

Copyright (c) 2008 by the American Institute of Aeronautics and Astronautics, Inc. The U.S. Government has a royalty-free license to exercise all rights under the copyright claimed herein for Governmental purposes. All other rights are reserved by the copyright owner.
} 


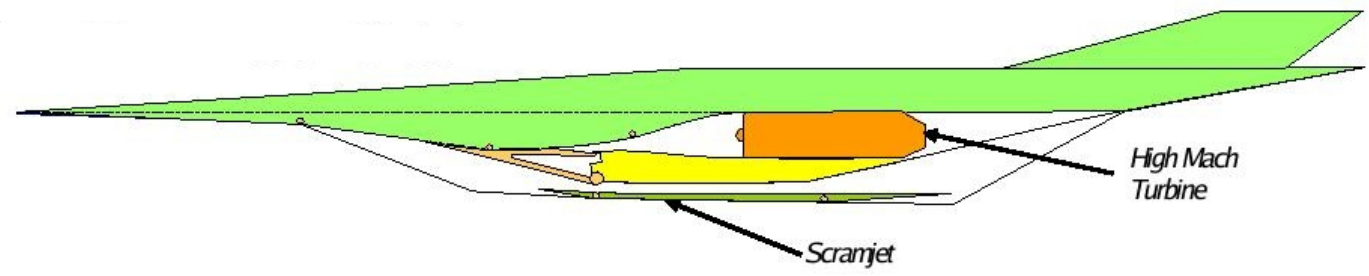

Figure 1. Conceptual arrangement of a TBCC flowpath.

flight Mach numbers from 4 to 7 . However, a TBCC transition test will require a Mach number simulation of about 3. A review of the facility hardware indicated that the facility could be operated at a Mach-3 enthalpy condition for at least 4.5 minutes. (TBCC flowpath transition tests will require longer test times than scramjet-only tests due to the need to allow time for the turbine hardware to spool up and/or down.) In order to develop this test capability, a new Mach-3 nozzle has been designed for the 8-Ft HTT. The final design has a throat radius slightly more than half the radius of the upstream mixing chamber, which raised the concern that large scale vortical structures created in the mixer might pass through the large throat and affect the nozzle-exit flow. This paper describes the aerodynamic-design process used for the new nozzle and three-dimensional, viscous, CFD simulations of the flowfield from the facility combustor to the the nozzle exit.

\section{The NASA Langley 8-Ft HTT}

The NASA Langley 8-Foot High Temperature Tunnel ${ }^{1}$ is a combustion-heated hypersonic blowdown-toatmosphere wind tunnel that has been used to provide flight enthalpy simulation for Mach numbers ranging from 4 to 7 . The open-jet test section is a 26 foot diameter sphere and can accommodate large air-breathing hypersonic propulsion systems. At these conditions, stable wind tunnel test conditions can be provided for periods up to 120 seconds. The high enthalpy/temperature test flow is achieved via the combustion of air and methane in a high-pressure facility combustor. For air-breathing propulsion tests, oxygen is added to the test medium so that the post-combustion test gas contains twenty-one percent molar oxygen.

The facility currently has three 8-ft exit-diameter nozzles with exit Mach numbers of 4,5 and 7 and one 54.5-inch exit-diameter nozzle with an exit Mach number of 5. The 8-ft diameter Mach 4 and 5 nozzles were designed to share the final 220 inches of the Mach-7 contour, which is permanently fixed in place. The 264 foot tunnel spans two large rooms and extends outside of the building. A bulkhead where the facility nozzle passes through the wall between rooms forms the interface between the upstream nozzle sections and the fixed 220-inch downstream section. For Mach-7 operation, the flow exiting the facility combustor passes through a transpirationally cooled throat section and expands in the Mach-7 nozzle to the test cabin. The Mach-7 configuration is shown in the upper half of Figure 2. For the Mach 4 and 5 test conditions, a section of the Mach-7 nozzle between the transpirationally cooled throat and the downstream bulkhead is removed and a mixer section and a lower Mach number nozzle are added to the flowpath (lower half of Figure 2). In the mixer, crossflow jets create shockwaves which drive the flow subsonic. These ambient-temperature air jets mix with the hot combustor flow to reduce the temperature to the target test enthalpy. From the mixer, the flow passes through a second throat and expansion section. The large scale Mach-4 and Mach-5 configurations have different throat and expansion sections up to the bulkhead. Downstream of the bulkhead they share the same contour as the Mach-7 configuration.

The mixer is also used with the 54.5-inch exit-diameter Mach-5 nozzle (named the M5HiQ nozzle due to the higher dynamic pressures that can be achieved) which has its own throat and downstream expansion section. This nozzle is not only smaller in diameter but also in length, measuring 206 inches from the throat to the end of the contour. Since the bulkhead is 181.6 inches downstream of the throat, the contour extends 24.4 inches downstream of the bulkhead. A 195.6-inch constant area pipe connects the contoured section of the nozzle to the test cabin. All of the nozzle hardware downstream of the bulkhead is mounted inside the downstream section of the fixed 8-ft exit-diameter section. Figure 3 shows a schematic of the M5HiQ nozzle 

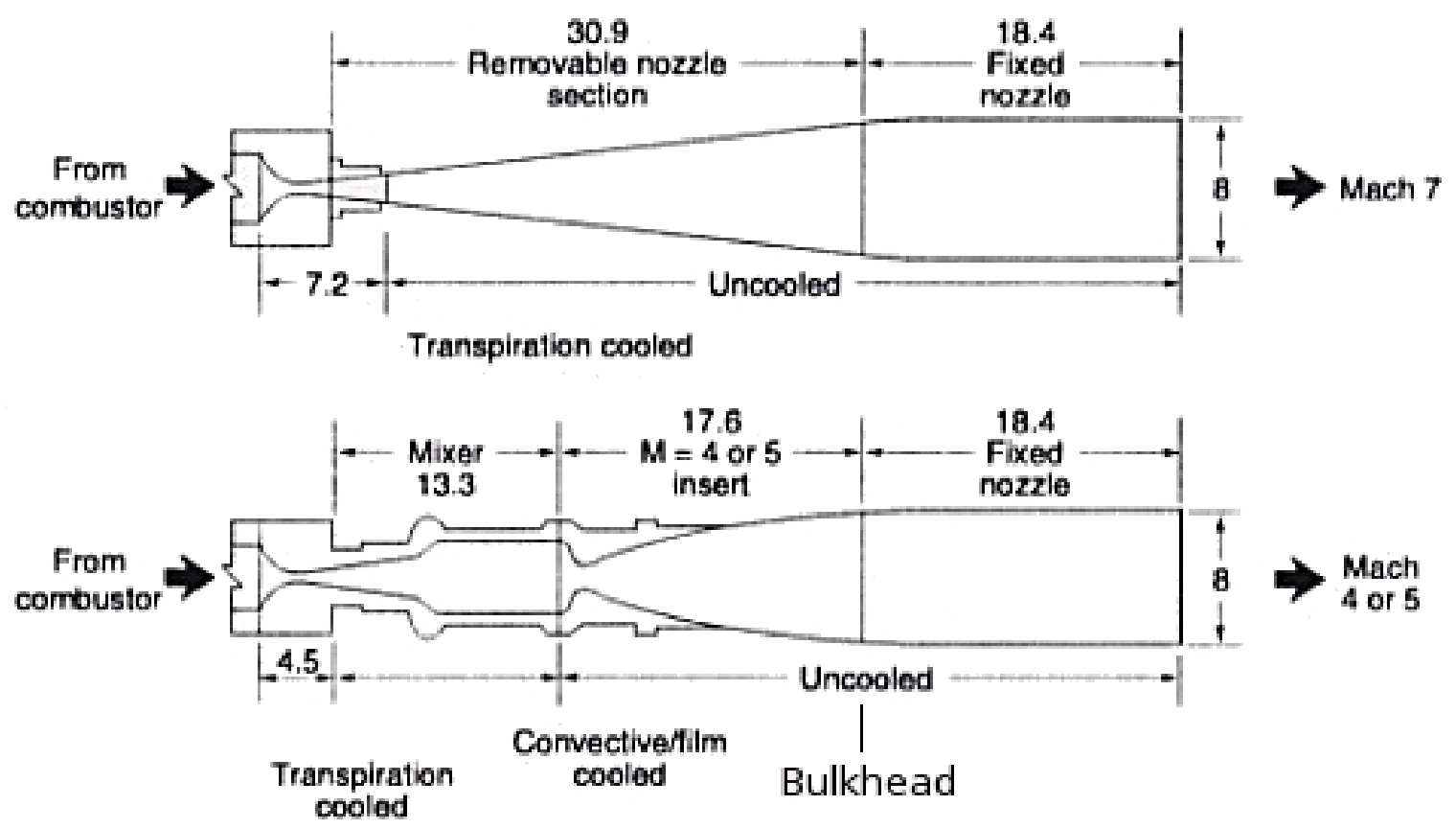

Figure 2. 8-Ft HTT Nozzle Configurations. (Dimensions in Feet)

installed in the 8-Ft HTT while Figure 4 is a photograph of the M5HiQ nozzle exit.

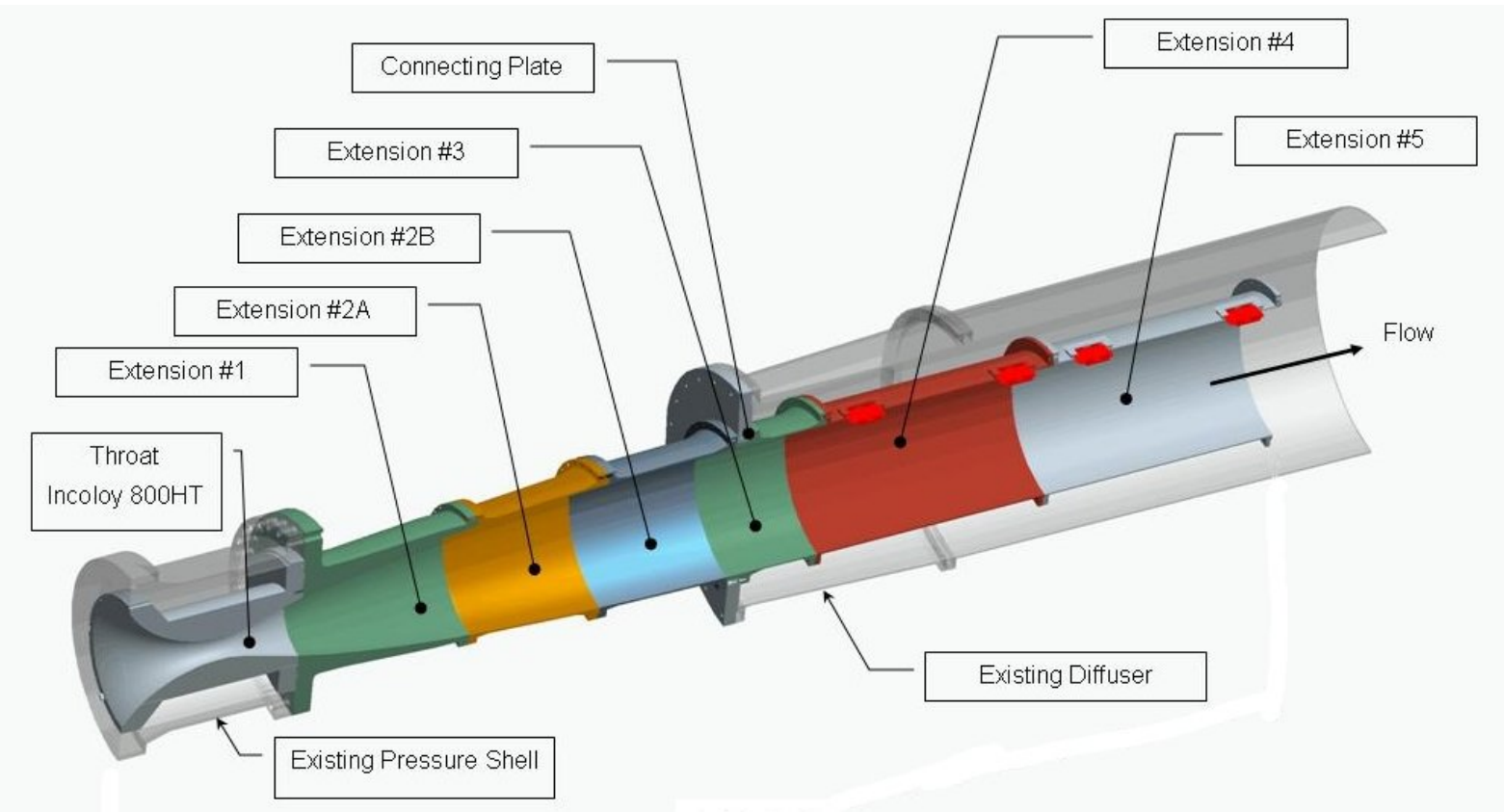

Figure 3. Schematic of the M5HiQ nozzle installed in the facility.

To simplify construction, transportation and installation, the M5HiQ nozzle was manufactured in pieces. Extension 3 of the nozzle begins 5.1 inches upstream of the bulkhead and includes the final 29.5 inches of the contoured section and the first 1.6 inches of the constant area section. The bulkhead was welded to 


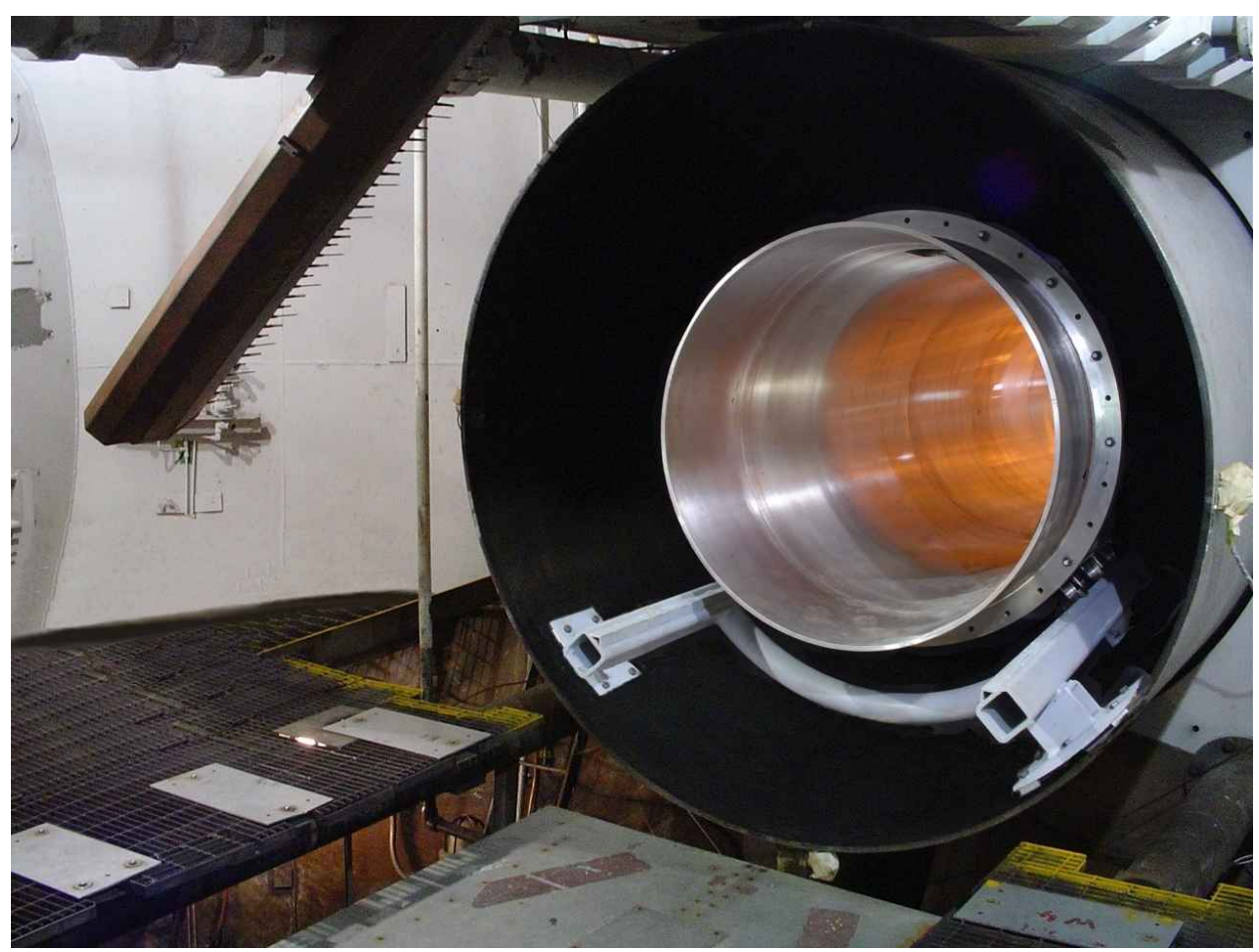

Figure 4. The exit of the M5HiQ nozzle installed in the facility.

extension 3 and forms a pressure vessel with the permanently fixed 220-inch section, test cabin and diffuser.

\section{Design Constraints}

During the conceptual design stage of the nozzle, it was realized that the contour in extension 3 of the M5HiQ nozzle was very shallow and if this segment could be used by the Mach-3 nozzle, a significant cost savings could be realized. (Reusing this extension saves not only the cost of constructing a new segment, but also the bulkhead which is part of this piece.) This requirement introduced several constraints to the design:

- The contour had to extend from the mixer exit to the start of extension 3

- The contour had to match the radius at the start of extension 3

- The contour had to match the slope at the start of extension 3

These are in addition to the usual constraints of providing uniform nozzle-exit flow at the target conditions and ensuring that the subsonic side of the contour matches the radius of the mixer section.

\section{Design Methodology}

Contours for the supersonic portion of the Mach-3 nozzle were generated using the IMOCND ${ }^{2,3}$ (Irrotational Method of Characteristics for Nozzle Design) code. This code requires the user to specify the throat and expansion surface of the nozzle and a target exit Mach number. From these, it generates a turning surface that produces uniform flow at the nozzle exit. The user can specify the throat and expansion surface in several different ways: a circular arc, a Gaussian curve or a polynomial curve. For the circular arc and Gaussian curve options, the user specifies a radius of curvature at the throat and the code determines, in an iterative fashion, the amount of expansion that will produce the target exit Mach number. The length of the nozzle is a function of the target exit Mach number, the throat radius of curvature and one physical 
dimension (i.e. exit radius). A larger throat radius of curvature produces a longer nozzle and a more gentle expansion of the flow. When viscous effects are considered, the longer nozzle usually produces a more uniform exit flow but at the expense of a thicker boundary layer.

There is no analytic method available for the design of the subsonic portion of the nozzle, although there are some general rules of thumb. These include keeping the contour and its 1st derivative continuous at the throat and properly specifying the radius of curvature in the throat region. The radius of curvature on the subsonic side of the contour affects the shape of the sonic line (which is actually curved) at the throat; a larger radius of curvature produces a flatter sonic line. Currently the IMOCND code starts the MOC solution with a flat sonic line, so a larger radius of curvature on the subsonic side of the contour gives a better approximation to this input line. For simplicity, often times the curve used for the supersonic side of the throat region is extended (or reflected) to the subsonic side. Since the subsonic contour must match some upstream geometry, it is typical to use a polynomial to smoothly transition from the subsonic side of the throat contour to the given upstream geometry.

The method of characteristics is an inviscid design method. In order to include viscous effects in the design, the flow quality resulting from the subsonic and IMOCND generated contours is evaluated with a Navier-Stokes CFD solver. Generally the CFD-computed exit properties will not match the target values due to the presence of the boundary layer. If this is the case, the target exit Mach number input into the IMOCND code is adjusted and a new contour generated. The new contour is evaluated with the CFD code and exit conditions checked. Additional iterations are made to achieve the target exit conditions. Generally this only requires a few iterations.

\section{Viscous CFD}

Viscous CFD calculations were performed with the VULCAN CFD code. ${ }^{4}$ This code solves the twodimensional, axisymmetric or three-dimensional Euler or Favre-averaged Navier-Stokes equations using a finite-volume discretization on a structured grid. Continuity equations for chemical species, including source terms for finite-rate chemical reaction, can be included as part of the calculation. There are a number of options for modeling thermodynamics, convective fluxes, and turbulence. For the nozzle design calculations, the axisymmetric thin-layer Navier-Stokes equations were solved. The gas was modeled thermodynamically as a mixture of thermally-perfect, calorically-imperfect gases. ${ }^{5}$ Roe's upwind flux difference split scheme ${ }^{6}$ with a 3rd order MUSCL stencil and a limiter by Van Leer $^{7}$ was used to model the convective fluxes. Turbulence was modeled using the k-omega model of Wilcox. ${ }^{8}$

The grid used in the design calculations had 1,409 points in the streamwise direction and 129 points in the radial direction. The geometry included 80 inches of the mixer section and the nozzle from the end of the mixer to the entrance of the test cabin (a total length of 514 inches). The grid was clustered near the wall in the radial direction resulting in a $\mathrm{y}+$ spacing of less than 0.8 along the length of the calculation.

The inflow boundary of of the computational domain was set to a subsonic inflow boundary condition. This boundary condition requires a total pressure, total temperature and a gas composition. The total conditions, given in Table 1, were determined from the target test conditions. The gas composition, given in Table 2, was computed from a chemical equilibrium calculation using the expected flow rates of air, oxygen and methane into the facility combustor and the mixer. Note that this boundary condition is based on the assumption that the flow at the inflow boundary is uniform. The outflow boundary was set to a supersonic outflow boundary condition which extrapolates all the flow properties from the interior to the boundary. For the final design, three calculations were made with different thermal wall boundary conditions. Two calculations were made with isothermal wall temperatures of 300 and $400 \mathrm{~K}$ and one calculation was made using an adiabatic wall boundary condition. For the adiabatic wall case, wall temperatures varied from 547 to $585 \mathrm{~K}$ along the length of the nozzle. For all three cases, iterative convergence between 6.5 and 11 orders of magnitude was achieved. 


\begin{tabular}{|c|ll|}
\hline Total Temperature & 1054 & Rankine \\
\hline Total Pressure & 64.3 & psi \\
\hline
\end{tabular}

Table 1. Design Mixer Conditions.

\begin{tabular}{|c|c|c|}
\hline Species & Mass Fraction & Mole Fraction \\
\hline $\mathrm{Ar}$ & 0.012434 & 0.009000 \\
$\mathrm{CO}_{2}$ & 0.015981 & 0.010500 \\
$\mathrm{H}_{2} \mathrm{O}$ & 0.013021 & 0.020900 \\
$\mathrm{~N}_{2}$ & 0.726504 & 0.749900 \\
$\mathrm{O}_{2}$ & 0.232060 & 0.209700 \\
\hline
\end{tabular}

Table 2. Test Gas Composition at the Mixer Exit.

\section{The Mach-3 Design}

The challenge in the new design was to develop an axisymmetric Mach-3 contour that would share the final 29.52 inches of the M5HiQ contour. This was accomplished by choosing a Gaussian-curve expansion section and adjusting the throat radius of curvature input into the IMOCND code to vary the length of the contour. The exit radius was set to 27.24 inches (the constant area radius) and the target Mach number set to 3 . The length was varied, via the throat radius of curvature, until the radius of the new contour matched the radius at the start of extension 3 (a radius of 27.1365 inches at an axial location 214 inches downstream of the mixer exit). This was an iterative procedure requiring several runs of the IMOCND code. This resulted in a Mach-3 contour that overlapped the M5HiQ contour from the match point to the end of the contour. The Mach-3 contour downstream of the match point was discarded and replaced with the M5HiQ contour and the constant area section. The new nozzle flowfield, from a point 80 inches upstream of the end of the mixer to the entrance of the test cabin, was computed with the VULCAN CFD code. Several iterations were made, adjusting the Mach number input into the IMOCND code, to achieve the target exit Mach number. Note that this procedure required an inner iteration to match the radius and an outer iteration to match the target exit Mach number.

There was a little bit of flexibility in specifying the length of the supersonic portion of the contour because the length of the subsonic contour was not fixed and could be adjusted as needed. The subsonic side of the throat contour was specified as a Gaussian curve that was connected to the 48 inch diameter mixer via a 4th order polynomial. At one end, the polynomial matched the radius, and the 1st and 2nd derivatives of the Gaussian curve. At the other end, the polynomial matched the 24 inch radius of the mixer with a slope of 60 degrees with respect to the nozzle centerline.

The above procedure produced a contour with the correct exit Mach number, and length and radius to match the pre-existing hardware. However, it resulted in a contour with a slope discontinuity of about 0.1 degrees at the match point. Fortunately the discontinuity in slope is small and is positioned near the end of the contour where the boundary layer is about 2.4 inches thick. The boundary layer helps to reduce the effects of the weak expansion fan that is created at this location. To further weaken the expansion wave, the slope discontinuity was removed by replacing 2 inches of the Mach-3 contour with a 3rd order polynomial, matching the radius and slope at each end. Note that this weakens the wave by spreading it out along the 2 inch segment, but does not remove it.

The final design was evaluated via a viscous CFD calculation and was found to have very uniform flow properties. The final contour and flowfield Mach number contours are shown in Figure 5 while the exit profiles of Mach number and static pressure are shown in Figure 6 for an isothermal wall temperature of 300 K. For this wall temperature the static pressure only varies by 0.32 percent across the exit and the Mach number only varies by 0.07 percent in the core. The results obtained with the isothermal wall temperature of $400 \mathrm{~K}$ and the adiabatic wall boundary have similar levels of non-uniformity. At the end of the constant 
area section (entrance to the test cabin) the boundary layer is between 4.3 and 4.9 inches thick, depending on the thermal boundary condition, giving a core flow diameter between 44.7 and 45.9 inches.

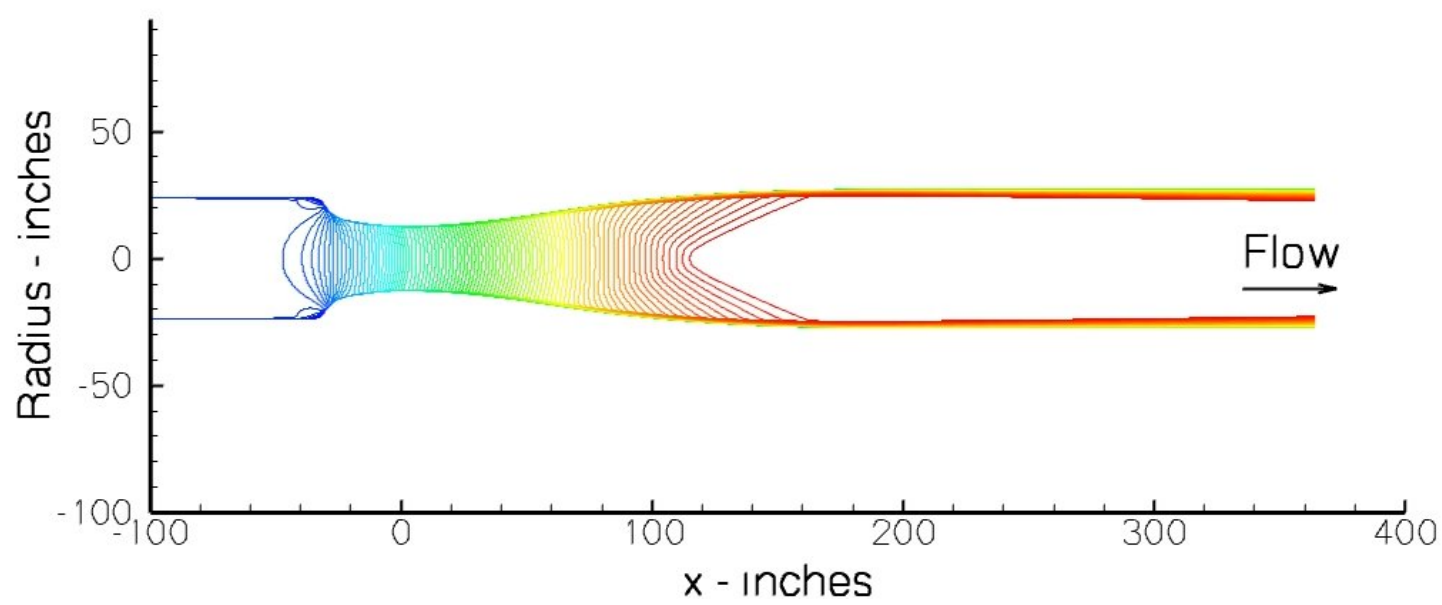

Figure 5. Mach number contours in the Mach-3 nozzle.

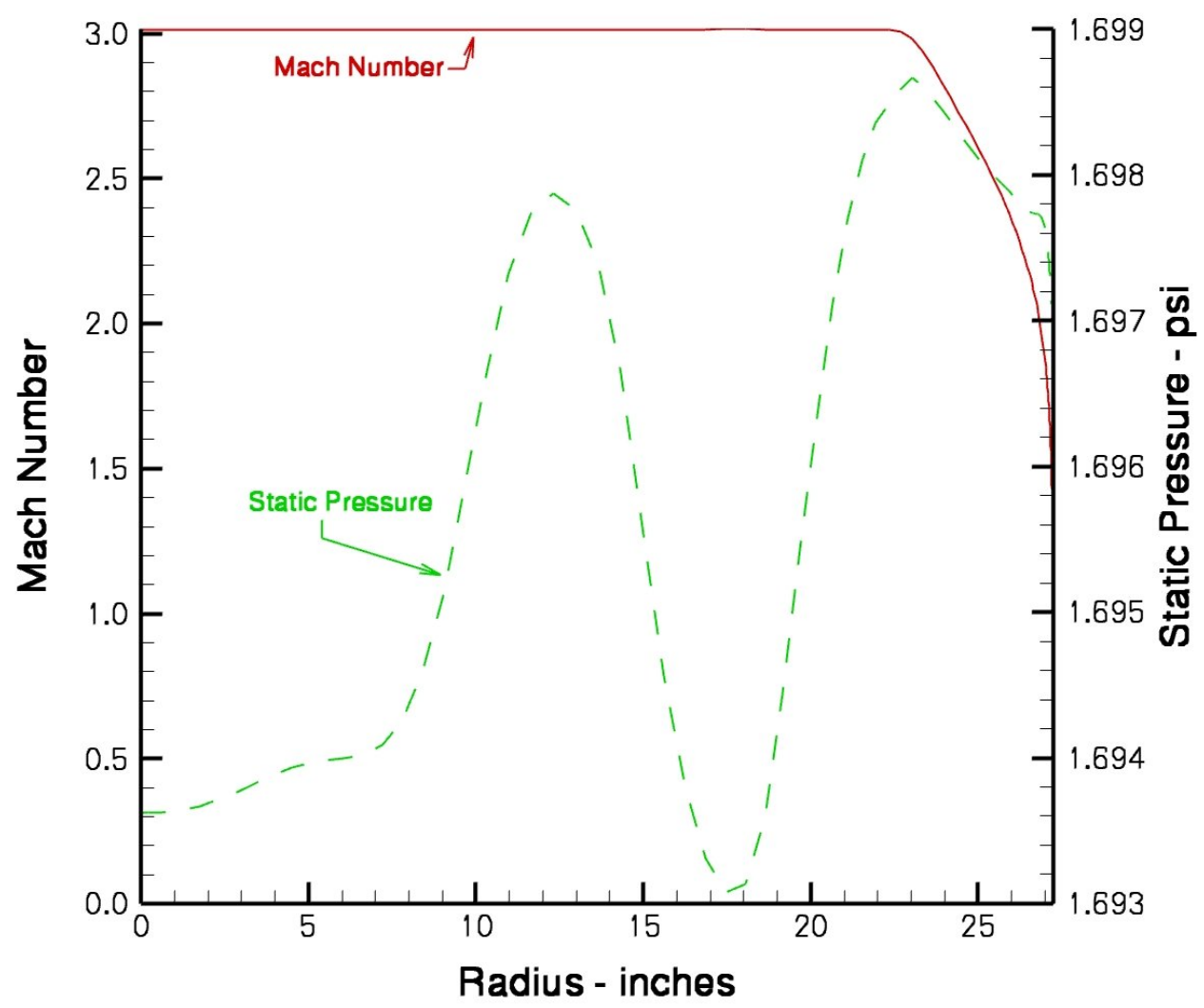

Figure 6. Nozzle exit profiles of Mach number and Pressure. 


\section{Mixer Flow Studies}

The new Mach-3 nozzle has a 25.31 inch diameter throat, which is a little larger than half of the 48 inch diameter mixer. This relatively large throat led to a concern that large scale flow structures created in the mixer by the crossflow air jets may persist downstream, pass through the throat and affect the nozzle-exit flow. If this were the case, it might be an indication that the hot combustor gases and cooler injected air had not properly mixed, leading to non-uniformity in other flow properties. Since both of these issues can have an impact on tests using the Mach-3 nozzle, a three-dimensional viscous CFD analysis of the facility flowpath, from the combustor exit to the test cabin entrance, was done to see if these scenarios were likely. To ensure confidence in the results, a simulation of the existing M5HiQ nozzle configuration was also performed and the results compared to nozzle-exit calibration data.

\section{A. Grid}

Grid generation for the tunnel flowpath posed several challenges, with respect to the size and complexity of the geometry and also the range of scales present. Figure 7 shows details of the mixer airflow circuits. The smallest dilution jet is of order 0.1 inch wide, while the computational domain is over 50 feet long. To overcome these challenges, geometrical symmetries in the circumferential direction were identified and the computational domain was modeled by a 60 degree section. This allowed all the dilution jets to be included in a periodic fashion and provided a balance between grid resolution and the ability to capture three-dimensional flow physics. The inflow boundary of the calculation was the exit plane of the combustor and the outflow boundary was the entrance plane of the test cabin. The grid for the Mach-3 nozzle configuration contains $8,990,720$ cells, and was split into 275 blocks for load balancing. It was produced using the GridPro ${ }^{9}$ software of the Program Development Company. The grid structure also allowed for two levels of coarsening, giving cell counts of 1,123,840 and 140,480 which provides the ability to perform grid sensitivity studies. A grid for the M5HiQ nozzle configuration was produced with an identical cell count.

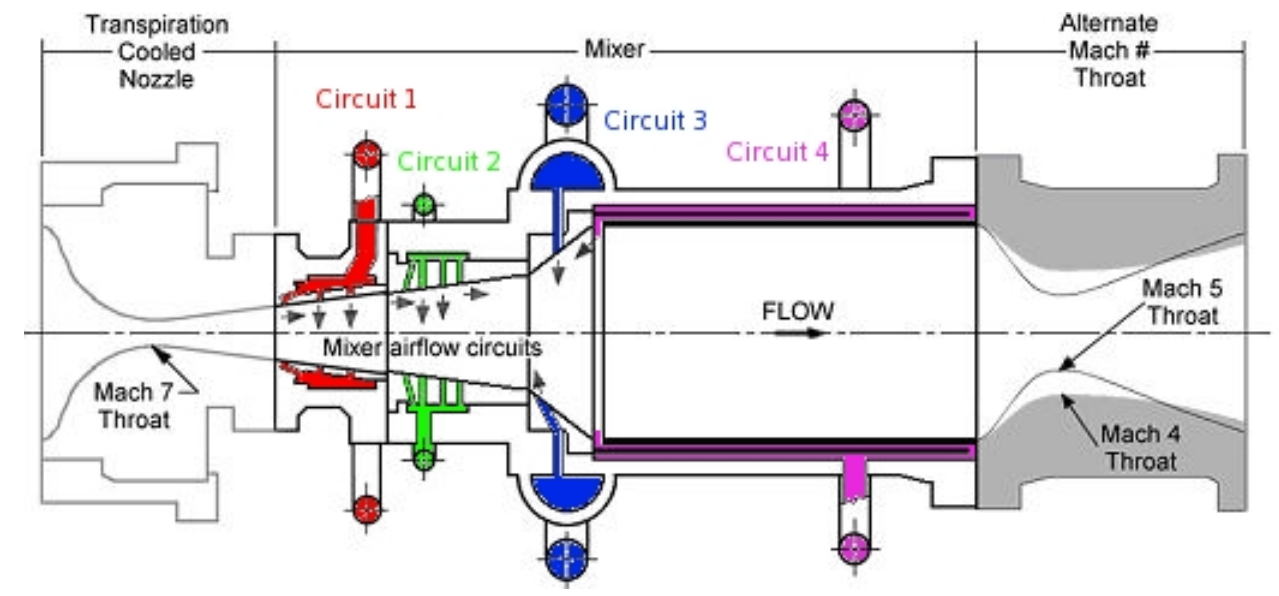

Figure 7. Facility Mixer.

\section{B. Boundary Conditions}

The facility combustor is operated at a limited number of well defined conditions where the combustor is known to operate in a stable fashion. For lower enthalpy test conditions, dilution air is added in the facility mixer. The mass flow through each ambient-temperature dilution jet was obtained via empirical correlations relating the expected pressure losses to the flow rates and balancing these against the specified total mass flow rates. The M5HiQ nozzle calculation was given the inflow conditions corresponding to 8-ft HTT Test 162, Run 20. Both sets of conditions are given in Table 3. 


\begin{tabular}{|c|c|c|c|c|c|}
\hline \multicolumn{2}{|c|}{ Inflow Condition } & \multicolumn{2}{|c|}{ Mach-3 Inflow } & \multicolumn{2}{c|}{ Mach-5 Inflow } \\
\cline { 2 - 6 } & $\begin{array}{c}\text { Mass Flow } \\
(\mathrm{kg} / \mathrm{s})\end{array}$ & $\begin{array}{c}\text { Temperature } \\
(\mathrm{K})\end{array}$ & $\begin{array}{c}\text { Mass Flow } \\
(\mathrm{kg} / \mathrm{s})\end{array}$ & $\begin{array}{c}\text { Temperature } \\
(\mathrm{K})\end{array}$ \\
\hline \multicolumn{2}{|c|}{ Combustor Inlet Plane } & 79.4 & 1111.0 & 104.3 & 1865.0 \\
\hline \multicolumn{2}{|c|}{ Transpiration Cooled Nozzle } & $20.9^{*}$ & 277.0 & $19.8^{*}$ & 277.0 \\
\hline \multirow{2}{*}{ Mixing Circuit 1 } & Slot & 76.2 & 277.0 & 3.37 & 277.0 \\
\cline { 2 - 6 } & Jets & 19.0 & 277.0 & 0.84 & 277.0 \\
\hline \multirow{2}{*}{ Mixing Circuit 2 } & Slot & 21.8 & 277.0 & 1.76 & 277.0 \\
\cline { 2 - 6 } & Jets & 19.1 & 277.0 & 1.54 & 277.0 \\
\cline { 2 - 6 } & Small Jets & 13.6 & 277.0 & 1.10 & 277.0 \\
\hline Mixing Circuit 3 & Jets & 0.0 & 277.0 & 0.0 & 277.0 \\
\hline Mixing Circuit 4 & Slot & 13.6 & 277.0 & 19.3 & 277.0 \\
\hline
\end{tabular}

Table 3. Table of inflow conditions for Mach-3 and Mach-5 tunnel configurations. (* - See explanation in main text)

\section{Combustor-exit plane}

The combustor-exit plane corresponds to the inflow of the computational domain. The combustor-exit properties were computed from a chemical equilibrium calculation using the facility combustor mass flow rates of air, oxygen and methane at the pressure needed to hit the target test conditions. This is similar to the calculation of the inflow properties used in the nozzle design calculations, but at the combustor exit instead of in the mixer. The gas compositions of the two cases are given in Table 4. To simplify the calculation, minor species were neglected in the equilibrium calculation, and the frozen chemistry assumption was used for the flow domain. Note that for both cases, the methane, oxygen and air are balanced to give a postcombustion oxygen mass fraction of 0.23 . There are three thermocouples at the end of the facility combustor which measured an average temperature of $3357 \mathrm{R}$ for the Mach-5 condition. The equilibrium calculation for this case produced a temperature of $3265 \mathrm{R}$.

\begin{tabular}{|c|c|c|}
\hline Species & $\begin{array}{c}\text { Mach-3 } \\
\text { Mass Fraction }\end{array}$ & $\begin{array}{c}\text { Mach-5 } \\
\text { Mass Fraction }\end{array}$ \\
\hline $\mathrm{O} 2$ & 0.2341 & 0.2381 \\
\hline $\mathrm{N} 2$ & 0.6892 & 0.5975 \\
\hline $\mathrm{CO} 2$ & 0.0422 & 0.0904 \\
\hline $\mathrm{H} 2 \mathrm{O}$ & 0.0345 & 0.0740 \\
\hline
\end{tabular}

Table 4. Table of combustor exit plane mass fractions for Mach-3 and Mach-5 tunnel configurations.

\section{Transpiration-cooled nozzle}

Due to the lack of a suitable model for a porous wall, the transpirationally cooled nozzle surface was not simulated. Instead, the region was modeled as a solid wall. However the mass that would have come through the wall was added to the inflow (combustor exit) boundary.

\section{Mixing circuit one}

There are four separate airflow circuits in the mixer. The first circuit consists of a wall-cooling slot and two sets of 6 transverse jets. The jets are equally spaced around the nozzle 60 degrees apart and are at two axial locations. The wall-cooling slot is upstream of the two rows of jets, and extends all the way around the nozzle. In order to calculate the flow split between the jets and the slot, it was assumed that both flows were choked. With this assumption, the area ratios can be used to determine the ratio of flow through each part of the circuit. 


\section{4. $\quad$ Mixing circuit two}

The second mixing circuit consists of a narrow wall cooling slot, two sets of transverse jets and a row of 256 fine jets equally spaced around the nozzle. The two sets of transverse jets are arranged like those of mixing circuit one, however they are offset in the circumferential direction by 30 degrees so they do not line up with the upstream circuit jets. Again the assumption of choked flow was used, and the total mass flow was split up according to area ratios. It should be noted that the 256 jets were not gridded up individually but rather were modeled as a transverse slot. Due to the fairly low mass flow and small size of the jets this does not have a significant effect on the flow. (Note from Table 3 that the mass flow for these small jets is only $5.2 \%$ of the total mass flow for the Mach- 3 case and $0.72 \%$ for the Mach- 5 case.)

\section{5. $\quad$ Mixing circuit three}

No flow entered the mixer via this circuit for either the Mach-3 or Mach-5 cases.

\section{Mixing circuit four}

The final mixing circuit consists of a slot at the upstream end of the settling chamber. This circuit is used to cool the liner of the settling chamber. Due to the pressure and temperature of the flow at this location, this boundary was modeled as a subsonic inflow.

\section{Exit and Walls}

A simple supersonic outflow boundary condition was used at the exit of the nozzle. In addition, the tunnel walls were assumed to be adiabatic. The two sides of the 60 degree pie slice were specified as symmetry conditions, as a generalized periodic boundary condition was not available in the code.

\section{Computations}

The simulation was run on the RTJones cluster at NASA Ames. This is a 512 node, 4096 core machine based on Intel Quad core processors. The runs were performed on 256 processors, with a wall time of about 9 hours. For the simulation, coarse-to-fine sequencing of the grids was used. Three levels were employed, with the coarsest level using every 4th cell, the medium level using every 2nd cell and the fine grid using all $8,990,720$ cells. First the coarse level was run to convergence, which is defined as a residual decrease of 7 orders of magnitude from the maximum value. The second level was then run until it reached the same residual level as the coarse grid. Finally the full grid was run until it reached a similar level of convergence as the others. The error in mass flow for the simulation was about $1 \%$.

\section{Results}

The first part of this section will be devoted to the M5HiQ simulation and how it compares to the available experimental data at the nozzle exit. After this, the Mach-3 simulation will be used to address the three areas of concern: how well the tunnel configuration mixes the dilution air, what sort of vortical structures are present and if structures propagate downstream to the test section.

\section{A. M5HiQ Simulation}

Nozzle exit properties for the M5HiQ configuration were obtained via a rake of total temperature, pitot and static pressure probes fixed to a pivot above the nozzle exit. This rake, called the Flow Survey Apparatus (FSA), is swept through the nozzle exit flowfield during nozzle calibration runs. Figures 8 and 9 show total temperature contours at the nozzle exit for the experiment and simulation. Recall that the downstream segments of the M5HiQ nozzle are mounted inside the fixed 8-ft exit-diameter section. The FSA is long enough to survey the 8-ft diameter nozzle and so it includes points (the small circles of Figure 8) outside of the M5HiQ exit flow. A comparison of the two plots shows an over-prediction of the CFD-computed total temperature by about $410 \mathrm{R}$. This can be attributed to several factors. First the specification of the combustor exit conditions were done assuming only major species in the products. By including minor species and accounting for dissociation we could expect a significant lowering of the temperature of the gas mixture. 
In addition, the frozen chemistry assumption would neglect the effects of dissociation and $N O_{x}$ formation that would most likely occur throughout the whole flow domain. Another probable cause of the temperature over prediction is the use of an adiabatic wall boundary condition for the simulation which prevents heat loss from the flow to the facility.

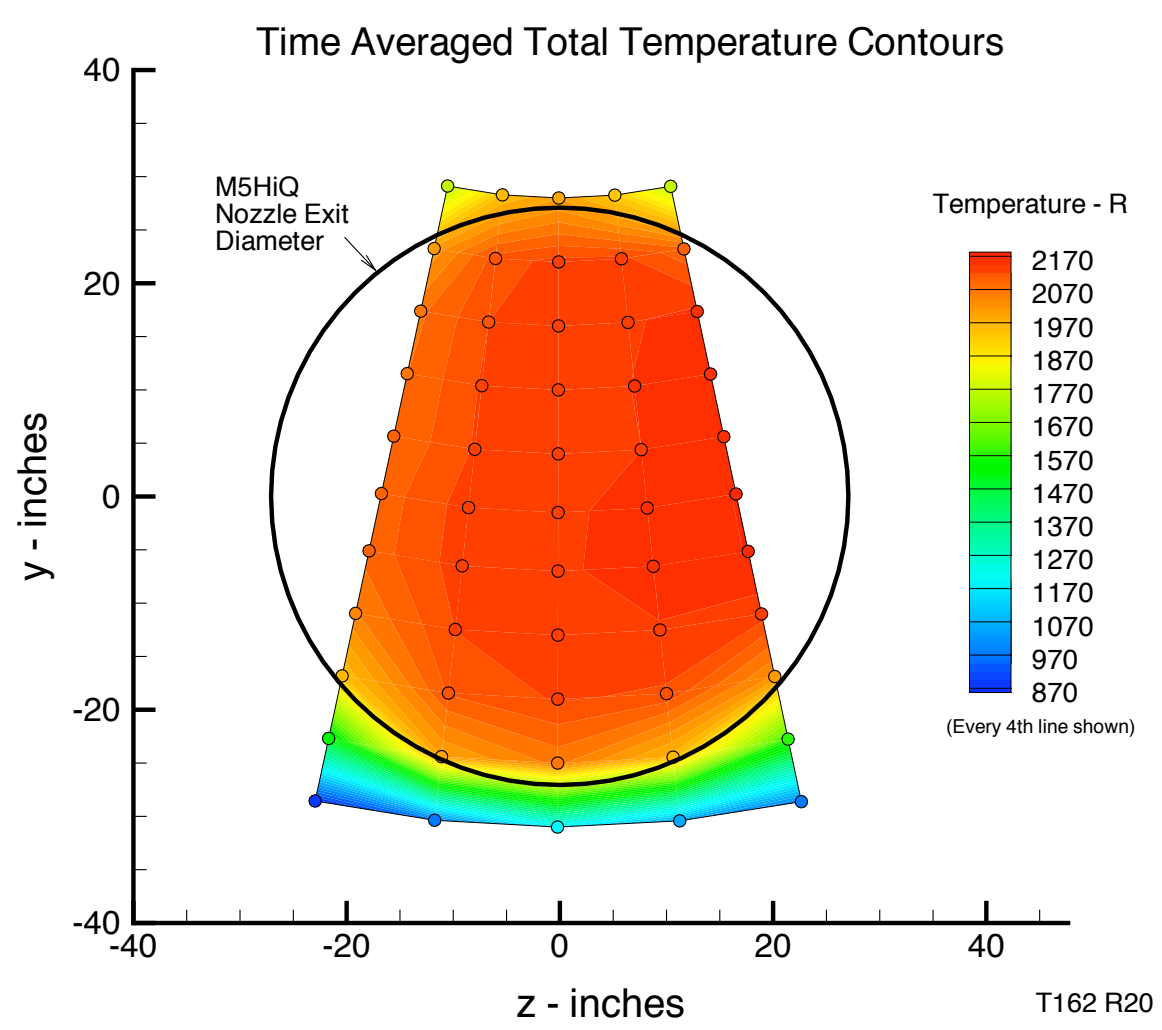

Figure 8. Total temperature measurements from the M5HiQ nozzle operation.

Although the magnitude of the total temperatures are different, both the experiment and CFD show a relatively uniform distribution. The boundary layer thickness cannot be compared between the two figures as the probe spacing on the FSA is too coarse to properly resolve the boundary layer. It can be concluded that the simulation results give a qualitative prediction of the experiment, however some caution needs to be taken when using the simulation results to predict absolute values of experimental data. Additional calculations will be made as part of future work to address the issues raised in this section.

\section{B. Mach-3 Flow Structure}

The Mach number profile at the exit of the Mach-3 nozzle is shown in Figure 10. As the profile shows, the core Mach number is only slightly greater than the design value. The boundary layer thickness compares well to the axisymmetric simulations shown in Figure 6. From this it can be concluded that the simulation is in good agreement with the expected results and that there is no major problem with the simulation.

To obtain some idea of the rotating nature of the flowfield, and thus the possibility of large vortical structures being present, the crossflow-velocity magnitude is used. The magnitude of the crossflow velocity is defined as $V=\sqrt{v^{2}+w^{2}}$ where $v$ and $w$ are the two crossflow-velocity components. Comparing this to the mean axial flow gives some indication of the strength of the swirling flow. 


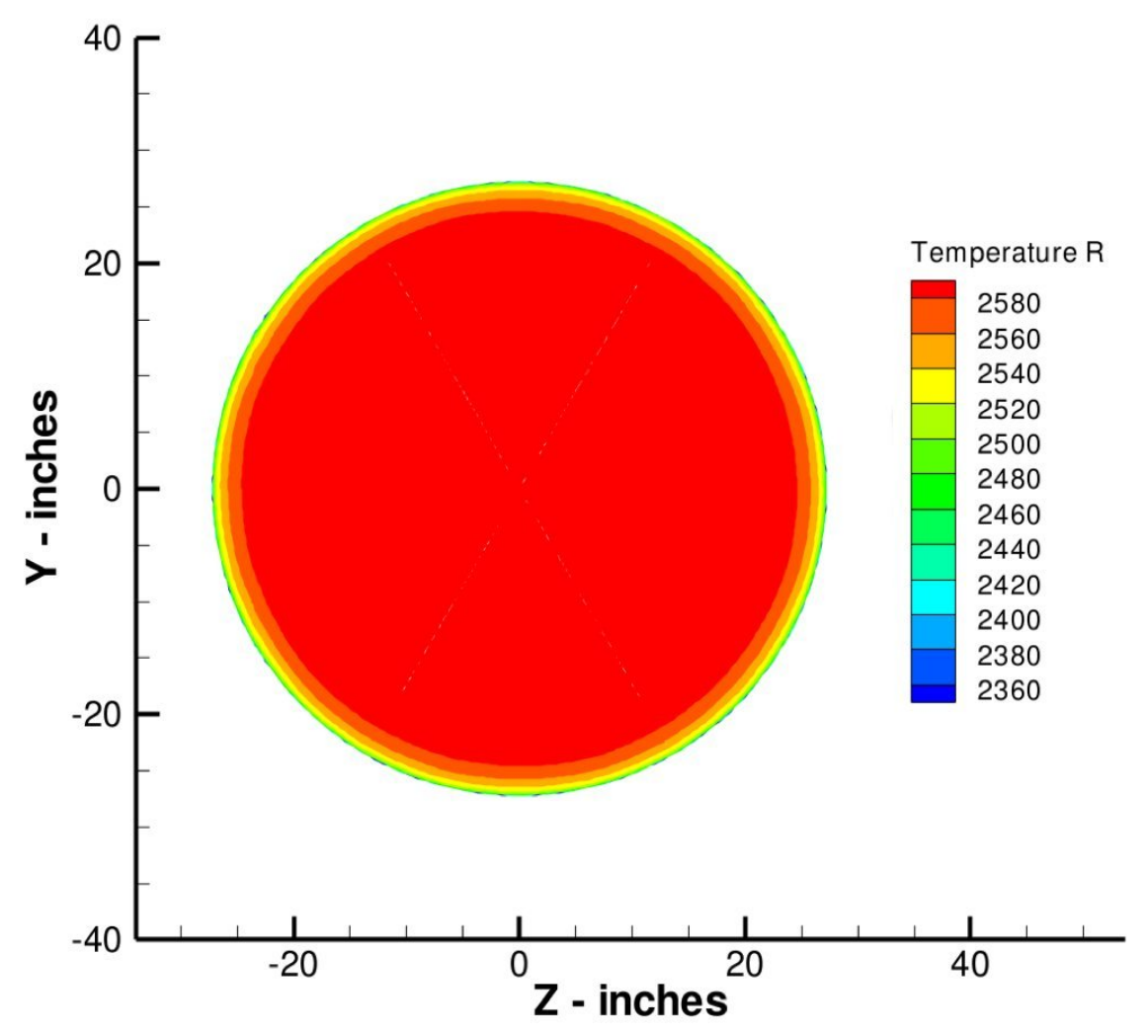

Figure 9. Total temperature results from the M5HiQ nozzle simulation.

In looking at the mixing of the dilution air with the combustor flow, good metrics are the total temperature and the mass fraction of $\mathrm{CO}_{2}$. The total temperature is a good metric because the combustor flow is hot while the dilution jets are ambient temperature. The species mass fraction of $\mathrm{CO}_{2}$ is a good metric because for this calculation, the dilution air was composed of only $\mathrm{O}_{2}$ and $\mathrm{N}_{2}$. As a result the combustor, which generates $\mathrm{CO}_{2}$ from the combustion of methane and oxygen-rich air, is the sole source of $\mathrm{CO}_{2}$. If the combustor flow and dilution flows are well mixed, both the total temperature and the $\mathrm{CO}_{2}$ at the mixer exit will be uniform.

Mach number contours in the vertical centerplane of the mixer section are shown in the left half of Figure 11. The flow accelerates from the combustor through the first part of the Mach-7 nozzle and encounters transverse jets at the start of the mixer section. Bow shocks form in front of these jets, reducing the Mach number of the flow. In the region of the sudden expansion of the settling chamber, (about 90 inches downstream of the Mach-7 throat) the flow becomes subsonic. The flow then passes through the settling chamber and re-accelerates to supersonic speeds in the throat of the Mach-3 nozzle. Turbulent diffusion levels, as indicated by the eddy viscosity ratio in the right half of Figure 11, show a significant amount of turbulent mixing throughout the mixer section, especially in the settling chamber.

Cross-section contour plots of crossflow-velocity magnitude with crossflow streamlines, taken at upstream and downstream ends of the constant-area mixer section (107 and 175 inches downstream of the Mach-7 nozzle throat), are shown in Figure 12. The mean axial velocity in the mixer is about $200 \mathrm{~m} / \mathrm{s}$, so crossflow velocities of $60 \mathrm{~m} / \mathrm{s}$ are significant. However, the swirling motion has decreased significantly by the end of the mixer, to a maximum value of about $7.5 \mathrm{~m} / \mathrm{s}$. Total temperatures in the same two crossflow planes are shown in Figure 13. There are large temperature gradients in the upstream plane which have decreased significantly by the time the flow reaches the downstream plane. Figure 14 shows contours of $\mathrm{CO}_{2}$ mass fraction at 


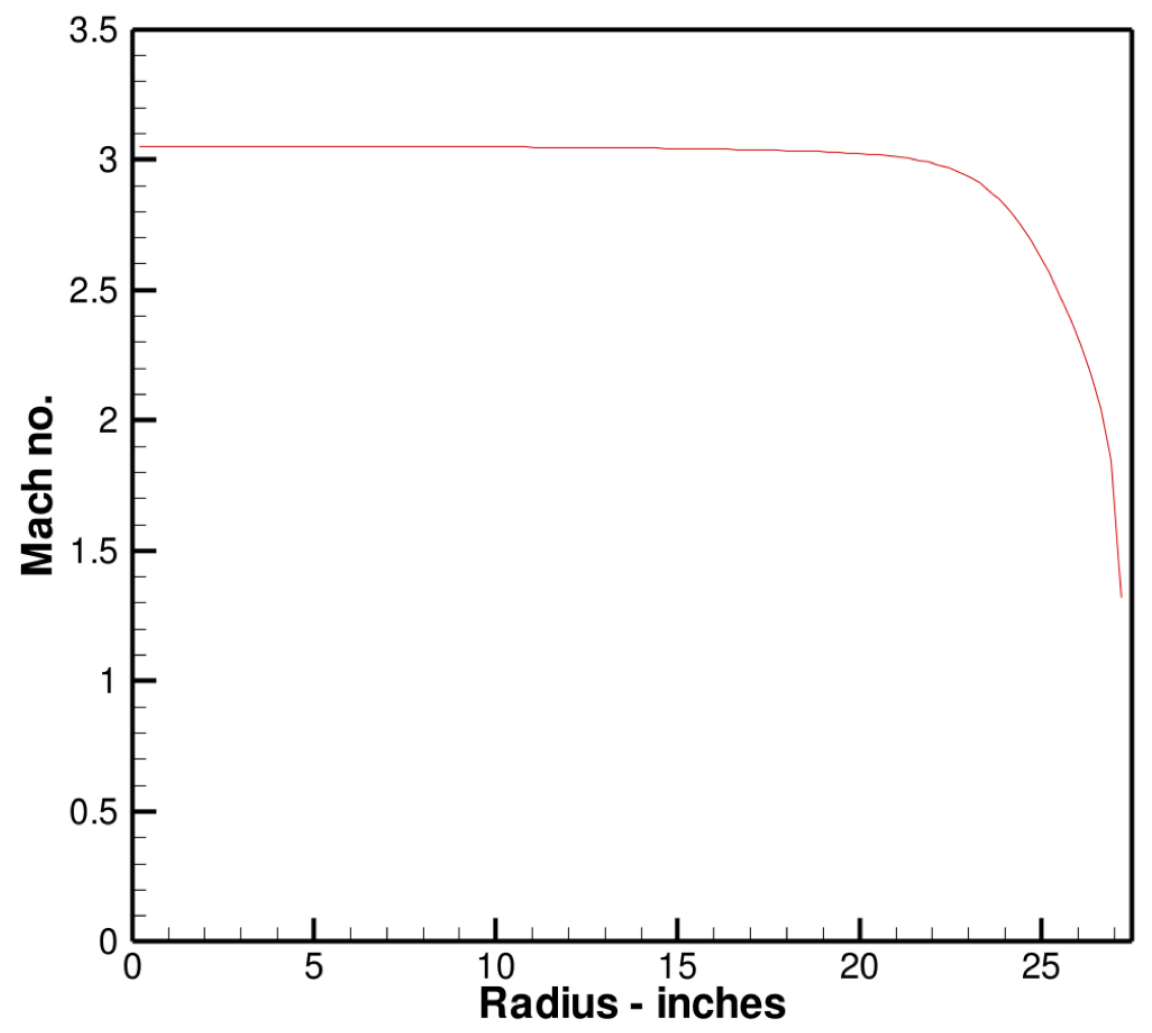

Figure 10. Mach number profile for Mach-3 simulation at the nozzle exit.

the same two locations. As with the crossflow velocities and the total temperature, non-uniformities at the upstream plane are greatly reduced by the time the flow reaches the downstream plane, indicating that the mixer is performing as intended.

At the nozzle exit (Figure 15), it can be seen that the magnitude of the crossflow velocity is even less than that at the end of the mixer. The maximum value of $1.4 \mathrm{~m} / \mathrm{s}$ is negligible compared to that of the main flow, which has a mean axial velocity of about $1,200.0 \mathrm{~m} / \mathrm{s}$. The exit-plane total temperature contours are shown in Figure 16. This shows a total temperature variation of about 10 to 20 degrees in the core flow. With a core total temperature of about $1040 \mathrm{R}$, the variation in core total temperature is less than 2 percent. The exit-plane contours for $\mathrm{CO}_{2}$ mass fraction are shown in Figure 17. The difference between maximum and minimum values is about $7 \times 10^{-5}$. This very small number indicates that the $\mathrm{CO}_{2}$ is is well mixed at the nozzle exit.

\section{Discussion}

A comment about the crossflow motion observed in Figure 12 is in order. The geometry used for the simulation is symmetric about the centerline in 60 degree slices, and one would not expect the flow to exhibit asymmetries in a steady state solution. Its asymmetry indicates that the symmetric solution is not stable and we could expect the flow to swirl either direction in the mixer section. Another consideration is the role played by the symmetry boundary conditions imposed on the domain. By limiting the flow to a 60 degree sector, the swirling motion is limited to one direction only. For a simulation of the whole (360 degree) geometry, it is possible that the flow would oscillate back and forth as is observed in many can-combustor-like flows.

This potentially unsteady artifact of the CFD solution does not change the conclusions drawn from the simulation. It is reasonable to assume that if the swirling flow does not propagate downstream to the 

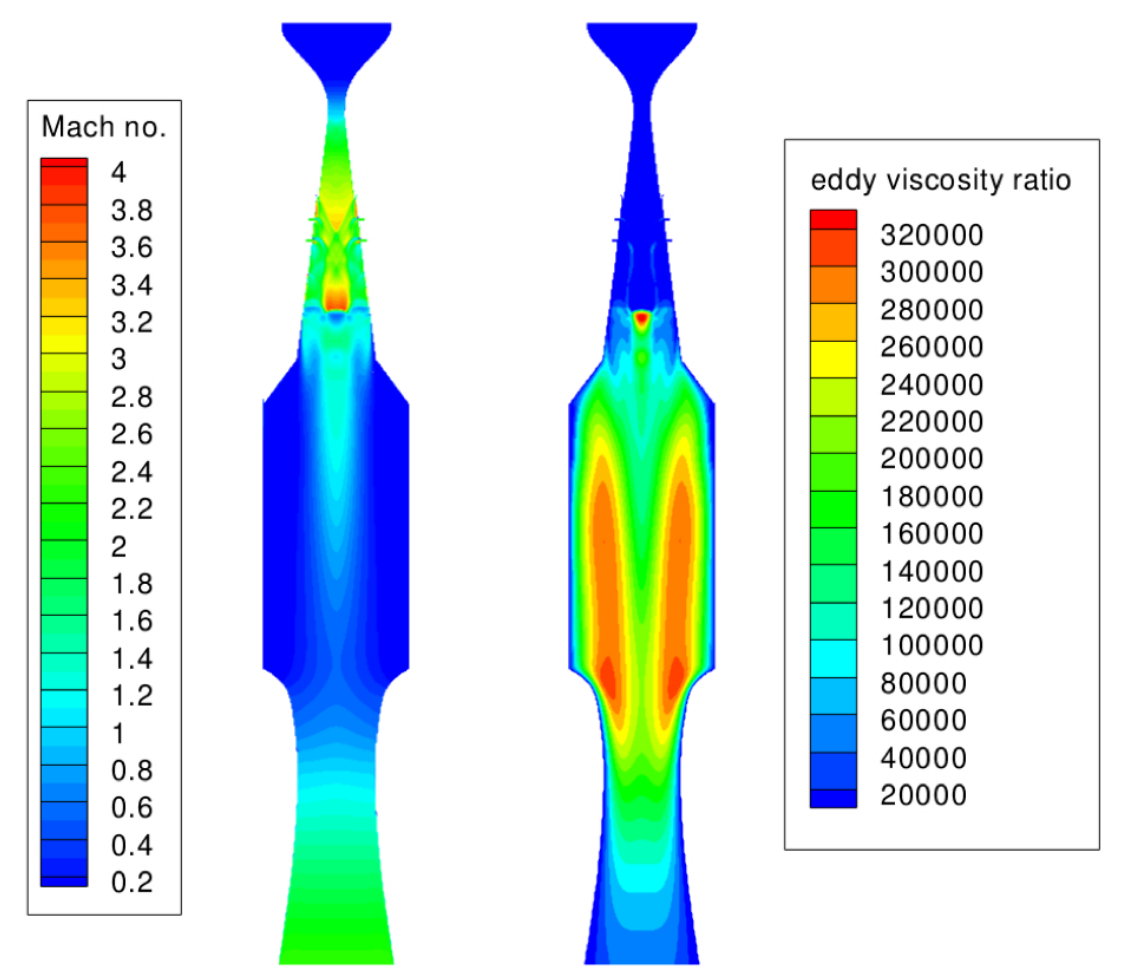

Figure 11. Mach number and eddy viscosity ratio contours in the centerplane for the Mach-3 simulation. The flow is from top to bottom. Note that only a short expansion section of the Mach-3 nozzle is shown.

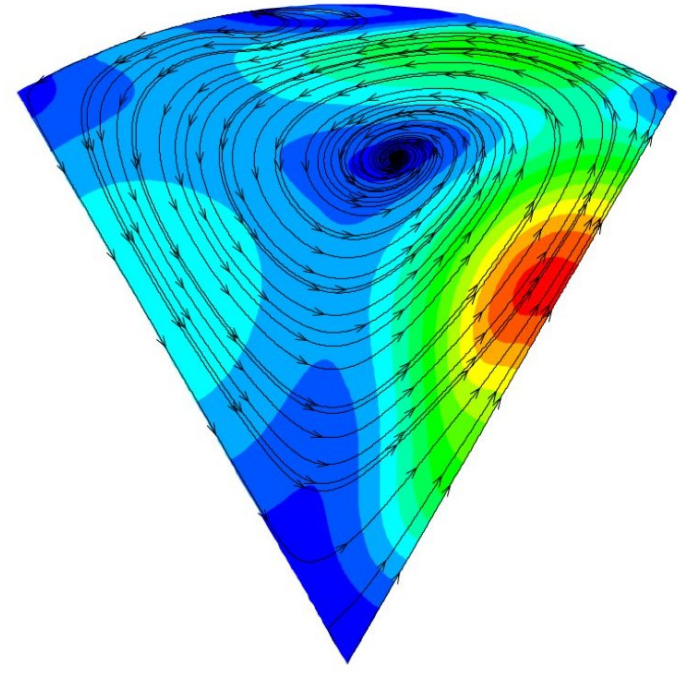

(a) 107 Inch Station

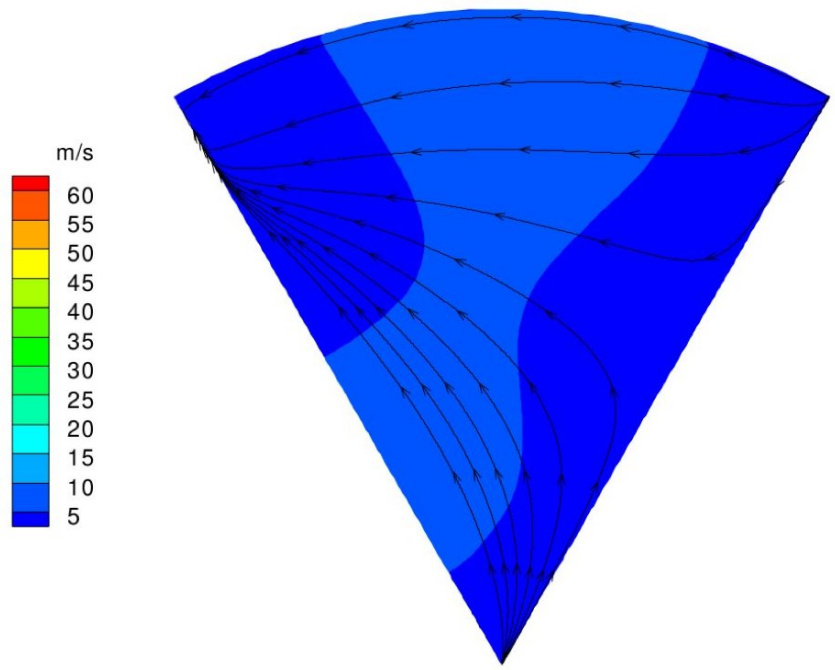

(b) 175 Inch Station

Figure 12. Streamline traces and contours of crossflow-velocity magnitude in the mixer (107 and 175 inch stations).

nozzle-exit plane for a steady solution, a fluctuating swirling flow would also not propagate. And it is also reasonable to assume that the scalar mixing would also not be affected by a fluctuating swirling flow. Indeed a fluctuating swirling flow could be expected to enhance the mixing process. 


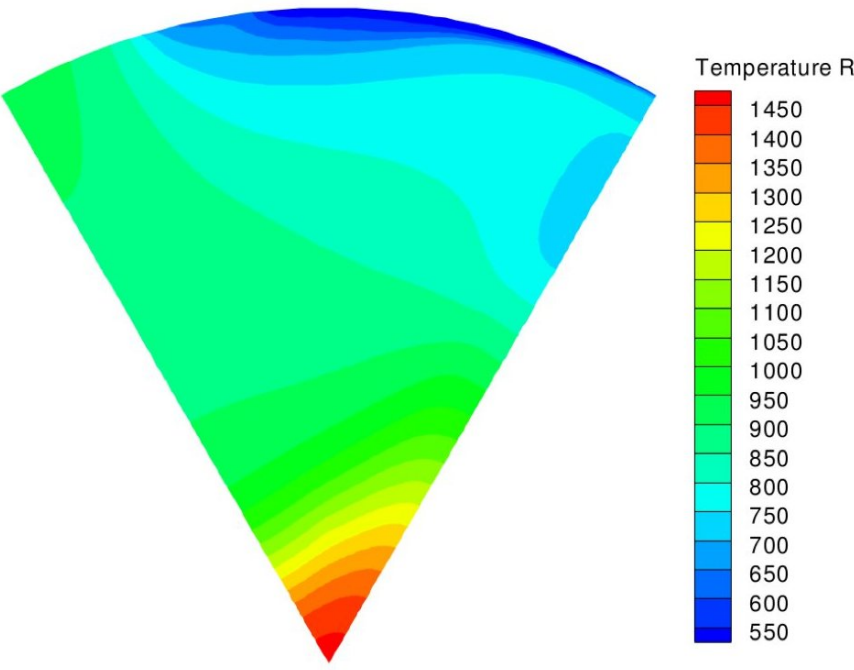

(a) 107 Inch Station

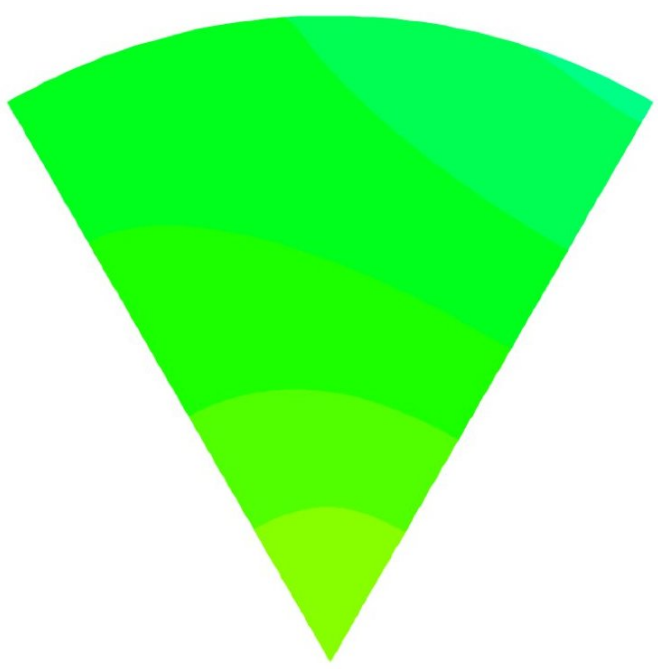

(b) 175 Inch Station

Figure 13. Total Temperatures in the mixer (107 and 175 inch stations).

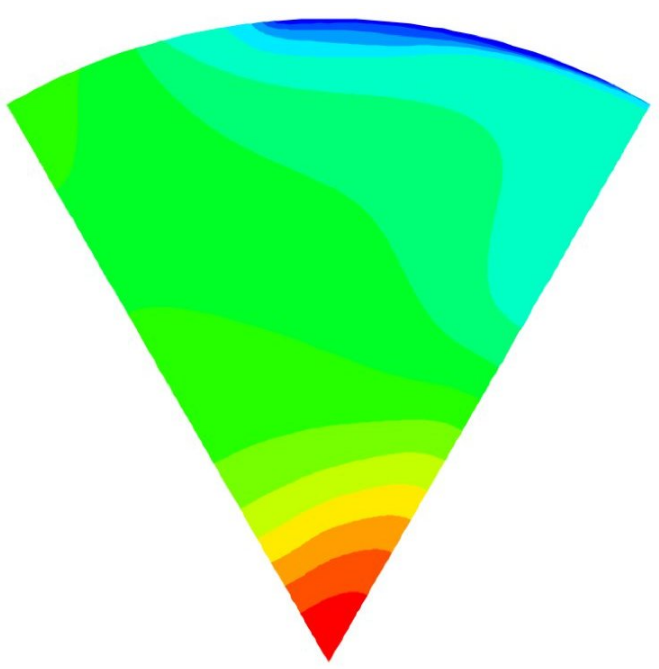

(a) 107 Inch Station

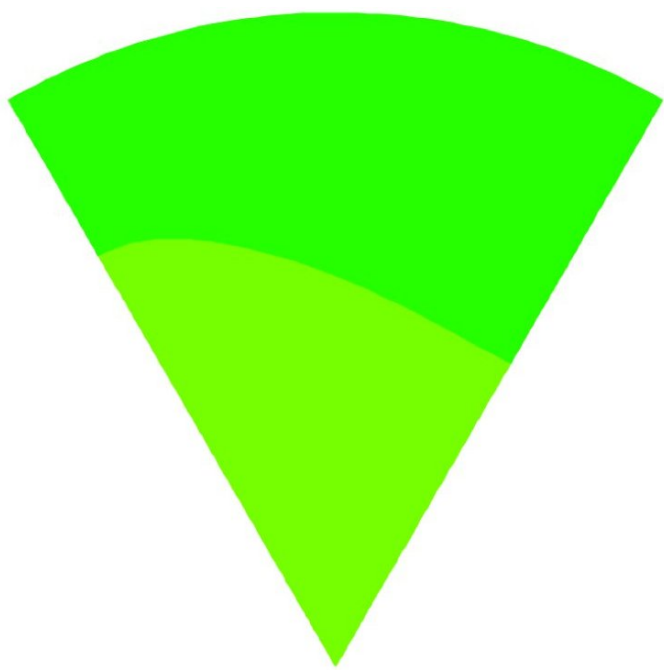

(b) 175 Inch Station

Figure 14. $\mathrm{CO}_{2}$ Mass fraction contours in the mixer (107 and 175 inch stations).

\section{Summary and Conclusions}

A new Mach-3 nozzle has been designed for the 8-Ft HTT which produces very uniform flow at the entrance to the test cabin. Axisymmetric CFD calculations show a pressure variation of only 0.32 percent across the nozzle exit while the Mach number varies by about 0.07 percent in the core. The boundary layer is about 4.9 inches thick at the nozzle exit giving a core size of 44.7 inches in diameter. Three-dimensional, viscous CFD calculations of the facility flowpath from the combustor exit to the entrance of the test cabin indicate that no significant large scale flow structures pass through the throat of the nozzle and adversely affect the quality of the nozzle-exit flow. In addition, the calculations indicate that the mixer is performing as intended so that the total temperature and species are well mixed by the end of the mixer and the nozzle exit. 


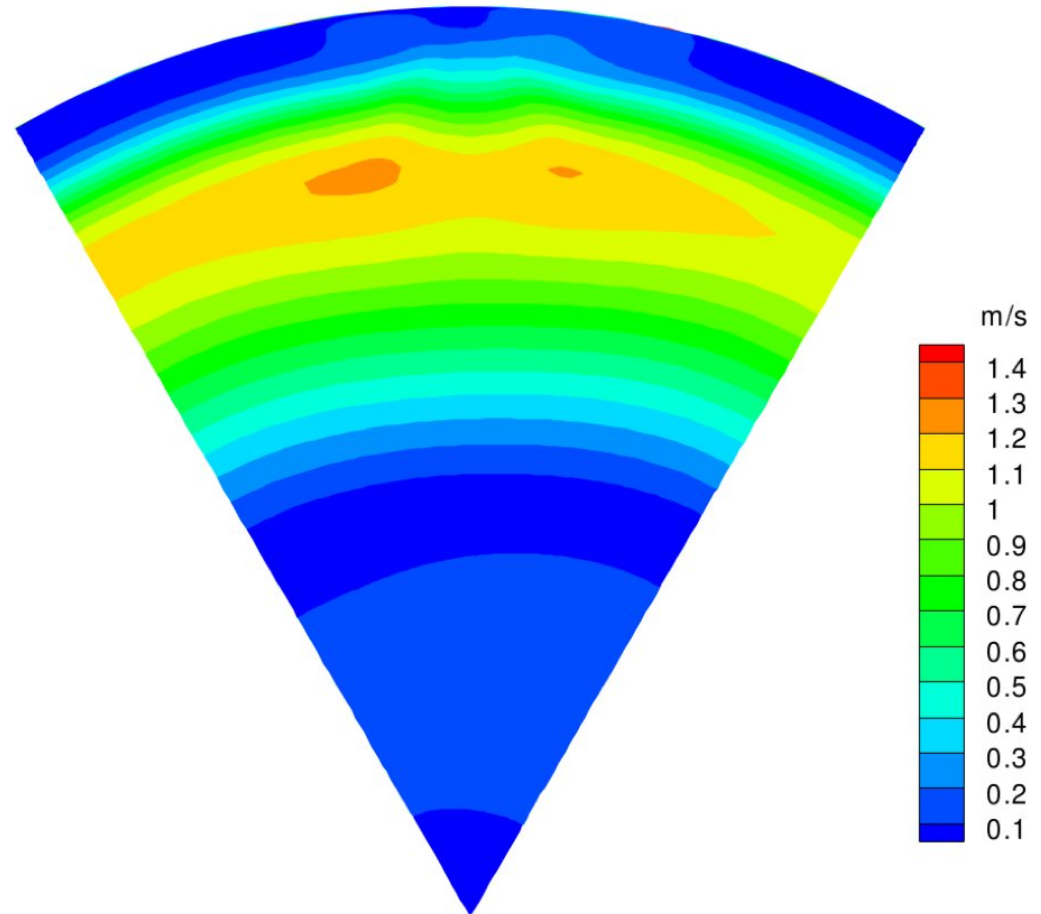

Figure 15. Contours of the crossflow-velocity magnitude in the nozzle exit plane.

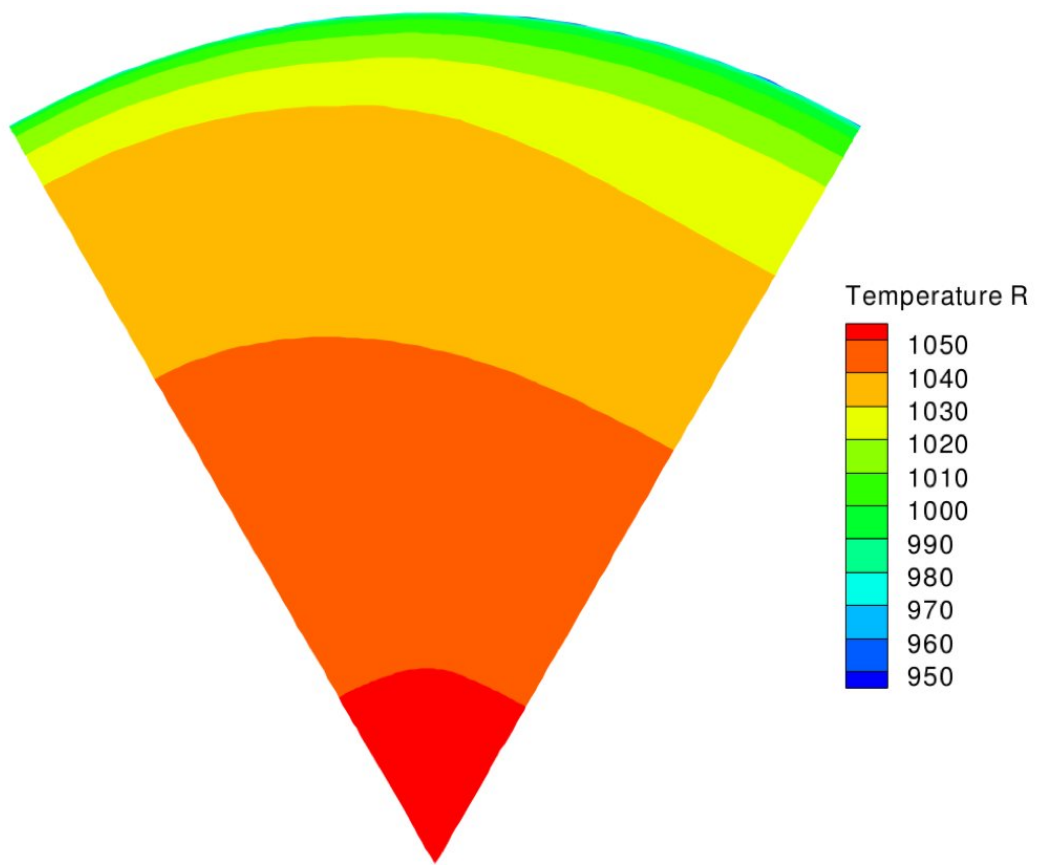

Figure 16. Contours of the total temperature in the nozzle exit plane.

\section{References}

${ }^{1}$ Guy, R. W., Rogers, R. C., Puster, R. L., Rock, K. E. and Diskin, G. L., "The NASA Langley Scramjet Test Complex," AIAA paper 96-3243, July, 1996. 


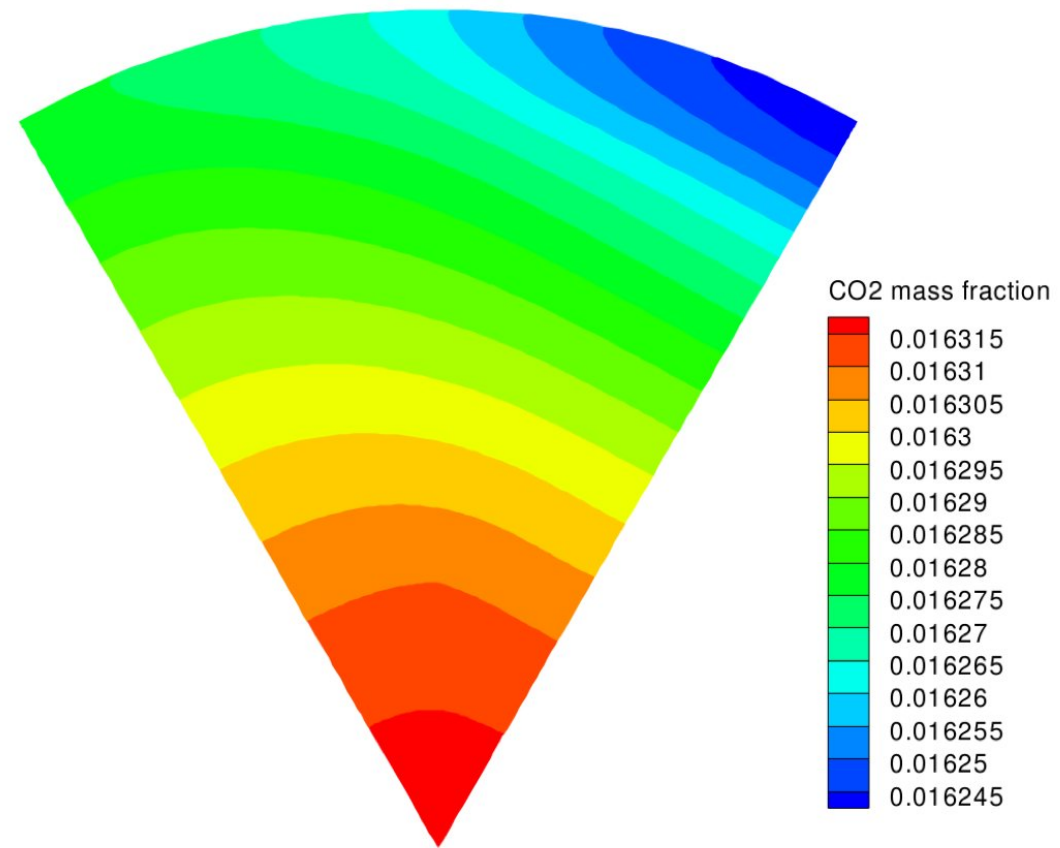

Figure 17. CO2 mass fraction contours in the nozzle exit plane.

${ }^{2}$ Gaffney, R. L. Jr,, "Design Of A Pulse-Facility Nozzle Using The Rotational Method Of Characteristics," Journal of Spacecraft and Rockets, Vol 43, Number 6, 2006.

${ }^{3}$ Gaffney, R. L., Jr., Stewart, B. K., Harvin, S. F., "The Design Of A High-Q, Mach-5 Nozzle For The NASA Langley 8-Foot HTT," AIAA paper No. 2006-2954, 2006.

${ }^{4}$ VULCAN, "http://vulcan-cfd.larc.nasa.gov", June 2008.

${ }^{5}$ McBride, B. J., Gordon, S. and Reno, M. A., "Thermodynamic Data for Fifty Elements," NASA TP-3287, January, 1993.

${ }^{6}$ Roe, P. L., "The Use of the Riemann Problem in Finite Difference Schemes," Proceedings of the Seventh International Conference on Numerical Methods in Fluid Dynamics, Stanford, California, June 23-27, 1980, Lecture Notes In Physics, Vol. 141, pp. 354-359. Springer-Verlag, Berlin, 1981.

${ }^{7}$ Hirsch, C., Numerical Computation of Internal and External Flows, Volume 2: Computational Methods for Inviscid and Viscous Flows, Chichester: John Whiley \& Sons, 1992.

${ }^{8}$ Wilcox, D. C., Turbulence Modeling for CFD, $2^{\text {nd }}$ ed., San Diego, Ca.: DCW Industries, 2006.

${ }^{9}$ Gridpro, AZ Graphic Manager Manual. Program Development Corp, 300 Hamilton Ave, Suite 409. White Plains, NY 10601. 